\title{
AVALIAÇÃO DA DISSIMILARIDADE GENÉTICA EM GENÓTIPOS DE BANANEIRA (MUSA SPP.) VIA MARCADORES RAPD ${ }^{1}$
}

\author{
CAROLINA MARIA PALÁCIOS DE SOUZA², ALEXANDRE PIO VIANA², CLÁUDIA FORTES FERREIRA ${ }^{3}$, \\ SEBASTIÃO DE OLIVEIRAE SILVA ${ }^{3}$, ALMY JUNIOR CORDEIRO DE CARVALHO², \\ PEDRO AMORIM BERBERT ${ }^{2}$, ELIAS FERNANDES DE SOUSA ${ }^{2}$
}

RESUMO - A bananicultura possui grande importância econômica e social. A UENF, por meio do Laboratório de Melhoramento Genético Vegetal iniciou um trabalho de introdução de cultivares de bananeira. Foram introduzidas cultivares com procedência da Embrapa Mandioca e Fruticultura e Embrapa Amazônia Ocidental. O objetivo deste trabalho foi realizar um estudo de diversidade genética entre 21 cultivares e obter a correta identificação de possíveis genótipos introduzidos na UENF. Foram avaliados os seguintes genótipos: Fhia 18, Prata-Anã, UENF 1526, Pacovan, Caipira, Maçã, UENF 1527, Nanicão, Thap Maeo, UENF 1528, UENF 1529, Grande Naine, Ambrósia, Bucaneiro, Calipso, PV42-68, PV42-85, PV42-142, ST12-31, Calcutta e BB da França. A análise de divergência genética foi feita com base na caracterização molecular, utilizando-se da técnica RAPD. Para serem obtidas marcas moleculares RAPD, foram utilizados 31 "primers", gerando um total de 94 marcas totais. Os resultados mostraram que os marcadores moleculares RAPD foram eficazes em revelar a existência de diversidade genética entre os 21 genótipos de bananeira. Na interpretação das análises moleculares, foi utilizado o complemento aritmético do Índice de Jaccard. Com base nas análises de agrupamento hierárquicas UPGMA e o método de otimização de Tocher, essa diversidade pôde ser observada pela presença de genótipos similares e divergentes.

Termos para indexação: dissimilaridade, marcadores moleculares, bananeira.

\section{EVALUATION OF GENETICS DISSIMILARITY IN BANANA TREE GENOTYPES (MUSA SPP.) BY MEANS OF RAPD MARKERS}

\begin{abstract}
Banana is a very important social and economic crop. The introduction of of banana cultivars was initiated through the Plant Genetics Laboratory at UENF. Cultivars from Embrapa Cassava and Tropical Fruits and Western Amazon were introduced. The objective of the present work was to analyze the genetic dissimilarity between 21 cultivars and obtain the correct identification of the possible genotypes introduced at UENF. The following genotypes were evaluated: Fhia 18, Prata Anã, UENF 1526, Pacovan, Caipira, Maçã, UENF 1527, Nanicão, Thap Maeo, UENF 1528, UENF 1529, Grande Naine, Ambrósia, Bucaneiro, Calipso, PV42-68, PV42-85, PV42-142, ST12-31, Calcutta and BB da França. The genetic dissimilarity was carried out using RAPD molecular markers. Thirty-one primers were used, generating a total of 94 bands. The RAPD molecular markers were capable to accurately reveal the existence of genetics diversity among the 21 banana genotypes. For data interpretation, the Jaccard index was used. Based on cluster analysis UPGMA and the Tocher method, the dissimilarity could be observed by the presence of similar and dissimilar genotypes. Index terms: dissimilarity, molecular markers, banana tree.
\end{abstract}

\section{INTRODUÇÃO}

As atividades de melhoramento genético da bananeira no Brasil tiveram início na Embrapa Mandioca e Fruticultura Tropical em 1983, com a introdução de germoplasma nacional e coleta em nível internacional, formando assim o Banco de Germoplasma de Banana (Silva et al., 1999). Os acessos (400) vêm sendo mantidos em campo, em Cruz das Almas (BA), na Embrapa Mandioca e Fruticultura Tropical (Silva \& SantosSerejo, 2003).

O sucesso de um programa de melhoramento genético depende fundamentalmente de algumas etapas, como a escolha de genitores que produzam indivíduos com a melhor combinação de alelos favoráveis e a seleção de genótipos superiores em populações segregantes. Com o advento das técnicas de biologia molecular, tornou-se possível a manipulação do DNA, que culminou no surgimento dos vários tipos de marcadores moleculares disponíveis atualmente (Lanza et al., 2000).

A tecnologia de marcadores moleculares pode contribuir significativamente para o conhecimento básico da cultura e do caráter estudado, e para a geração e desenvolvimento de produtos melhorados (Ferreira \& Grattapaglia, 1998). Já foram desenvolvidos sistemas de marcadores de DNA em Musa para ajudar na administração do germoplasma, seleção dentro do complexo gênico ou introgressão de espécies silvestres, e para diagnose de doenças (Crouch et al., 1998).

As análises de RAPD estão baseadas no fato de que cada iniciador arbitrário dirige a síntese de vários segmentos de

'(Trabalho 137-07).Recebido em:24-05-2007. Aceito para publicação em:14-12-2007.

${ }^{2}$ Universidade Estadual do Norte Fluminense Darcy Ribeiro, Centro de Ciências e Tecnologias Agropecuárias, Av. Alberto Lamego, 2000, Horto, CEP 28015-620 Campos dos Goytacazes- RJ.

${ }^{3}$ Embrapa Mandioca e Fruticultura Tropical, Rua Embrapa, s/n ${ }^{\circ}$. CEP 44380-000 Cruz das Almas-BA. 
DNA, simultaneamente, em diversos pontos no genoma, resultando assim em várias bandas com pesos moleculares diferentes, a depender do tamanho do segmento do DNA amplificado. Uma vez estabelecido o "fingerprint" do genoma em questão, várias informações podem ser obtidas, o que pode ser comprovado pela ampla utilização da técnica para estudos em microrganismos, plantas e animais (Sharon et al., 1992; Oakley et al., 1998; Singh \& Roy, 2001; Urasaki et al., 2002; Vitória et al., 2004).

Wesh \& McClelland (1990) e Williams et al. (1990) introduziram uma técnica que se baseia na detecção de polimorfismo de DNA amplificado ao acaso (RAPD-Random Amplified Polymorphic DNA), usando oligonucleotídeos de dez bases. Essa técnica tem-se mostrado eficiente na identificação da variabilidade genética em diversos grupos de plantas e pode ser usada como uma ferramenta auxiliar em programas de melhoramento.

De Jesus et al. (2006) empregaram os marcadores tipo RAPD e microssatélite para a diferenciação molecular de cultivares-elite de bananeira. Os marcadores permitiram a separação das cultivares de acordo com a origem e a constituição genômica, e definiram padrões moleculares para as várias cultivares avaliadas.

Damasco et al. (1996) identificaram um marcador RAPD capaz de discriminar variantes somaclonais de 'Cavendish' apresentando a característica de nanismo.

O objetivo deste trabalho foi realizar um estudo de diversidade genética entre as 21 cultivares introduzidas na UENF com propósito de obter uma base para o programa de melhoramento genético e, além disso, obter a correta identificação de possíveis genótipos introduzidos.

\section{MATERIAL E MÉTODOS}

\section{Material Genético}

Foram avaliados 21 genótipos de bananeira. Esses 21 genótipos foram introduzidos em pesquisas anteriores na Universidade Estadual do Norte Fluminense Darcy Ribeiro (UENF), em um experimento que foi instalado na área experimental da Universidade, localizada na Escola Agrícola Estadual Antônio Sarlo. Foram avaliados os seguintes genótipos: Fhia 18, PrataAnã, UENF 1526, Pacovan, Caipira, Maçã, UENF 1527, Nanicão, Thap Maeo, UENF 1528, UENF 1529, Grande Naine, Ambrósia, Bucaneiro, Calipso, PV42-68, PV42-85, PV42-142, ST12-31, Calcutta e BB da França.

\section{Isolamento do DNA Genômico}

O DNA genômico foi isolado de acordo com o protocolo descrito por Doyle \& Doyle (1990) com algumas modificações. Foram utilizadas amostras de folhas jovens de cada genótipo. As lâminas foliares, sem a nervura central, foram coletadas em gelo no campo e armazenadas a $-70^{\circ} \mathrm{C}$ em ultrafreezer. Foram maceradas em almofariz de porcelana, contendo nitrogênio líquido, até a obtenção de um pó fino. Foram transferidos, aproximadamente, $300 \mathrm{mg}$ de material macerado e congelado para microtubos Eppendorf de 2,0 mL. Posteriormente, foram adicionado $1.000 \mu \mathrm{L}$ de tampão de extração, incubaram-se os tubos em banho-maria a $65^{\circ} \mathrm{C}$, por 40 minutos.

Os tubos foram retirados do banho-maria e centrifugados aproximadamente por cinco minutos, a $10.956,40 \mathrm{G}$ em microcentrífuga Eppendorf, transferindo-se $900 \mu \mathrm{L}$ do sobrenadante para novos tubos de 2,0 mL. Foram adicionados ao sobrenadante $900 \mu \mathrm{L}$ de clorofórmio-álcool isoamílico (24:1) e novamente foram centrifugados. A fase superior $(800 \mu \mathrm{L})$ foi transferida com micropipeta de $1.000 \mu \mathrm{L}$ para novo tubo de $2,0 \mathrm{~mL}$, que recebeu $800 \mu \mathrm{L}$ de clorofórmio-álcool isoamílico, procedendo nova centrifugação. A fase superior foi transferida para um novo tubo $(1,5 \mathrm{~mL})$, e foram adicionados $2 / 3$ do volume de isopropanol gelado. Os tubos foram incubados a $4^{\circ} \mathrm{C}$ durante a noite.

As amostras foram centrifugadas ainda geladas por dez minutos, a 10.956,40 G. Um precipitado branco formou-se no fundo do tubo. O sobrenadante foi removido, e o precipitado foi lavado duas vezes com $100 \mu \mathrm{L}$ de etanol $70 \%$ e uma vez com $100 \mu \mathrm{L}$ de etanol $95 \%$. As amostras de DNA foram deixadas à temperatura ambiente por 20 minutos para secagem, e então, ressuspendidas em $200 \mu \mathrm{L}$ de TE (10mM Tris-HCl, $1 \mathrm{mM}$ EDTA, pH 8,0) contendo RNAse na concentração final de $4,0 \mu \mathrm{L} \mathrm{mL}^{-1}$. Incubaram-se as amostras a $37^{\circ} \mathrm{C}$, por 30 minutos, e, posteriormente, adicionaramse $40 \mu \mathrm{L}$ de $\mathrm{NaCl}(2,5 \mathrm{M})$ na proporção de $1: 10(\mathrm{NaCl}$ : DNA ressuspenso) e $2 / 3$ de isopropanol gelado aos tubos $(160 \mu \mathrm{L})$, que foram mantidos em geladeira a $4^{\circ} \mathrm{C}$ durante a noite. Em seguida, as amostras foram centrifugadas por 10 minutos, a 10.956,40 G, lavadas com etanol, como já mencionado anteriormente, desidratadas e ressuspendidas em volume final de $100 \mu \mathrm{L}$ de água milli-Q.

A determinação da concentração de DNA foi baseada na quantificação obtida por meio da análise comparativa em gel de agarose a $0.8 \%$, na presença de brometo de etídio. Como padrão de referência para quantificação, foi utilizado o plasmídeo pGEM $_{112}$ adicionado ao gel nas concentrações 25ng, 50ng, 80ng e 100ng. As amostras foram padronizadas em $25 \mathrm{ng} \mu \mathrm{L}^{-1}$ para serem utilizadas nas análises de RAPD

\section{Seleção de iniciadores e PCR}

Foi feita, de forma prévia, uma triagem de iniciadores, utilizando-se de 52 iniciadores, tendo como critérios de escolha, em ordem decrescente de prioridade, um grande número de bandas totais e um grande número de bandas polimórficas.

As reações de amplificação foram realizadas conforme Williams et al. (1990), com modificações, no volume final de $20 \mu \mathrm{L}$ e contendo os reagentes nas seguintes concentrações: $12,68 \mu \mathrm{L}$ de água; $2,0 \mu \mathrm{L}$ de tampão $10 \mathrm{X} ; 1,6 \mu \mathrm{L}$ de $\mathrm{MgCl}_{2} ; 1,0 \mu \mathrm{L}$ de dNTPs; $1,6 \mu \mathrm{L}$ de iniciador e 0,12 unidade de Taq DNA polimerase produzida na UENF. Foram utilizados microtubos para PCR, nos quais foi colocado $1 \mu \mathrm{L}$ de DNA e, paralelamente, preparado um mix contendo um iniciador diferente. Dessa solução, foram retirados $19 \mu \mathrm{L}$ e adicionados aos microtubos, totalizando os 20 $\mu \mathrm{L}$ da reação

Foi utilizado o termociclador (Perkin Elmer GeneAmp PCR System 9700) programado para $95^{\circ} \mathrm{C}$, por 1 minuto, seguido de 45 ciclos de 1 minuto a $94^{\circ} \mathrm{C}, 1$ minuto a $36^{\circ} \mathrm{C}$ e 2 minutos a $72^{\circ} \mathrm{C}$, 
e uma etapa final para extensão de 7 minutos a $72{ }^{\circ} \mathrm{C}$, utilizando o modo de transição de temperatura mais rápida, $1{ }^{\circ} \mathrm{C} \mathrm{Seg}{ }^{-1}$. Os produtos amplificados (bandas) foram obtidos por meio de eletroforese em gel de agarose a 1,2\% e visualizados após coloração por brometo de etídio. Os perfis de RAPD de cada genótipo foram obtidos somente pela presença (1) e ausência (0) de bandas de alta densidade.

\section{RAPD \\ Análise da dissimilaridade Genética via Marcadores}

Na interpretação das análises moleculares, foi utilizado o complemento aritmético do Índice de Jaccard.

Posteriormente, foi adotado o método hierárquico UPGMA para o agrupamento. No procedimento analítico, partindo-se da matriz de distâncias genéticas, procedeu-se a sucessivas identificações dos genótipos mais próximos, a partir do par mais semelhante, até que se estabeleceu um diagrama de árvore. (Cruz 2001)

Os dados obtidos foram analisados pelo Programa Genes

\section{RESULTADOS E DISCUSSÃO}

Da triagem inicial, foram utilizados 31 iniciadores (Tabela 01), gerando 94 marcas ao todo, sendo 75 marcas polimórficas e 19 marcas monomórficas, ou seja, em média, cada iniciador gerou 2,42 marcas polimórficas e 0,61 marcas monomórficas. Verifica-se que o número de marcas totais variou entre 1 e 4 marcas por iniciador, e que $79,79 \%$ das marcas apresentaram polimorfismo.

Ferreira et al. (2004), no trabalho de caracterização molecular de banana, encontraram um total de 150 marcas polimórficas que foram obtidas pela amplificação de 21 iniciadores, utilizando a técnica de RAPD.

Howell et al. (1994), usando a técnica de RAPD, identificaram 116 produtos de amplificação em germoplasma de Musa, usando nove iniciadores. Nesse caso, a técnica foi utilizada para identificar e classificar o germoplasma de Musa. Damasco et al. (1996) utilizaram 66 iniciadores ao acaso na triagem de vários genótipos de Musa; dos 66 iniciadores, 19 (28,8\%) revelaram polimorfismo entre as plantas do gênero $M u s a$, usando a técnica de RAPD.

Pillay et al. (2000) utilizaram 80 iniciadores na amplificação do DNA, usando a técnica RAPD em $M$. acuminata subsp. burmannicoides clone 'Calcutta 4' (AA genomes) e $M$. balbisiana clone 'Honduras' (BB genomes). Três iniciadores (A17, A18 e D10) produziram um único fragmento específico do genoma, e duas espécies foram identificadas.

\section{Análise de agrupamento}

Na Figura 2, está apresentado o dendograma da distância genética dos 21 genótipos de bananeira com base em marcadores RAPD, obtido pelo complemento aritmético do índice de Jaccard, utilizando-se do método hierárquico UPGMA (Unweighted Pair Group Method with Arithmetic mean). Observa-se que houve a formação de oito grupos. O primeiro grupo foi formado pelos genótipos Fhia 18, PV 42-85 e Calipso que, apesar de se tratar de cultivares tetraplóides, apresentam características diferentes. A PV42-85 é um híbrido da Pacovan, que é uma mutação da Prata Comum. A Fhia 18 é um híbrido da Prata-Anã cujas plantas são completamente diferentes das plantas do subgrupo Prata (Prata Comum e Pacovan), embora a Prata-Anã produza um fruto semelhante ao da Pacovan. Teoricamente, as presenças do genoma B na Fhia 18 e PV 42-85 podem diferenciá-las da Calipso. Por outro lado, esses genótipos possuem $3 \mathrm{X}$ complementos cromossômicos de Musa acuminata, o que poderia explicar tal ligação.

O segundo grupo foi formado pelos genótipos Pacovan, PV 42-142 e BB da França, um triplóide, um tetraplóide e um diplóide. Pacovan e PV 42-142 são, respectivamente, uma variedade e um híbrido desta variedade. A presença da contribuição genômica $\mathrm{B}$ nos três genótipos deve ter levado a agrupá-los juntos (Figura 2).

O terceiro grupo foi formado pelos genótipos Prata-Anã, UENF 1527, Caipira, Grande Naine e UENF 1529. Caipira, UENF 1527 e Grande Naine são do mesmo grupo genômico (AAA). Os dois complementos genômicos AA da Prata-Anã e da UENF 1529 podem ser semelhantes aos das cultivares anteriores. $\mathrm{Na}$ identificação de possíveis genótipos introduzidos na UENF, como o do acesso UENF 1527, ficou claro que essa cultivar pode tratar-se da cultivar Caipira. O acesso UENF 1529 foi introduzido como o genótipo Prata Zulu e foi classificado junto à Prata-Anã (Figura 2).

O quarto grupo foi formado pelos genótipos UENF 1526 e Ambrósia. A cultivar Ambrósia, híbrido de Gros Michel, está classificada junto com Bucaneiro e Calipso. Essa classificação deve-se ao fato de as cultivares serem tetraplóides. $\mathrm{O}$ acesso UENF 1526, que inicialmente se considerava como a cultivar Fhia 18 , não se trata da mesma, pois esta foi classificada no primeiro grupo, apresentando, então, uma grande distância entre ambas. O quinto grupo foi formado pelos genótipos Nanicão e Bucaneiro. A cultivar Nanicão está classificada junto com a Grande Naine por pertenceram ao mesmo subgrupo. Da mesma forma que a cultivar Bucaneiro, deveria estar junto com a Calipso. Por outro lado, a presença de apenas complementos genômicos de Musa acuminata pode levar à classificação observada.

O sexto grupo foi formado pelos genótipos PV 42-68, ST 12-31 e UENF 1528. A cultivar PV 42-68 deveria enquadrar-se melhor no grupo 2 por ser um híbrido da Pacovan. Considerando que a Pacovan é uma mutação da Prata e ST 12-31 é a Prata 'São Tomé', a semelhança entre PV 42-68 e ST 12-31 pode ser justificada devido a esse fato. A presença do genoma B pode ter levado a agrupar o acesso UENF 1528. Este, por sua vez, não se trata da cultivar Thap Maeo, como relatada em sua introdução inicial, na coleção.

O sétimo grupo ficou formado pelos genótipos Maçã e Calcutta. A cultivar Maçã possui dois terços de seus cromossomos semelhantes aos da Calcutta. O oitavo e último grupo ficou com o genótipo Thap Maeo. 


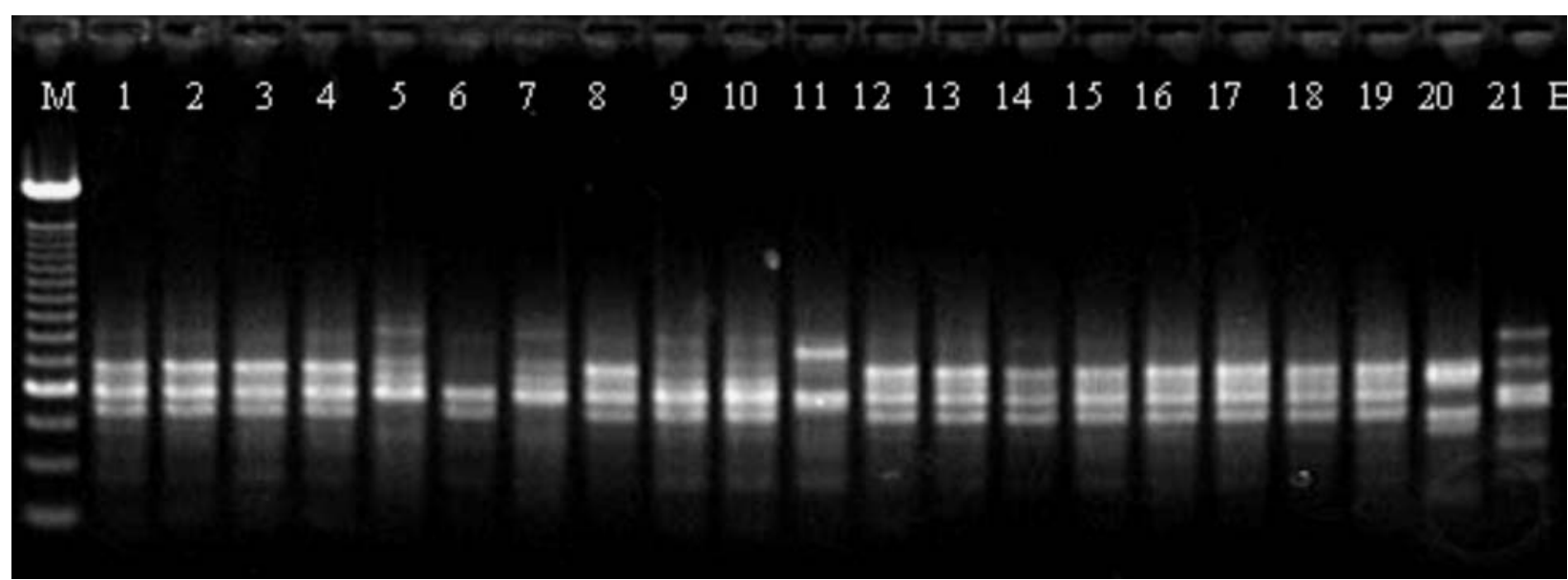

FIGURA 1- Amplificação com o "primer" OPD 03. M- Marcador de DNA (Lambda clivado com PST I);1-Fhia 18; 2- Prata Anã; 3- UENF 1526; 4- Pacovan; 5- Caipira; 6- Maçã; 7- UENF 1527; 8Nanicão; 9- Thap Maeo; 10- UENF 1528; 11- UENF 1529; 12- Grande Naine; 13- Ambrósia; 14- Bucaneiro; 15- Calipso; 16- PV42-68; 17- PV42-85; 18- PV42-142; 19- ST12-31; 20Calcutta; 21-BB da França.

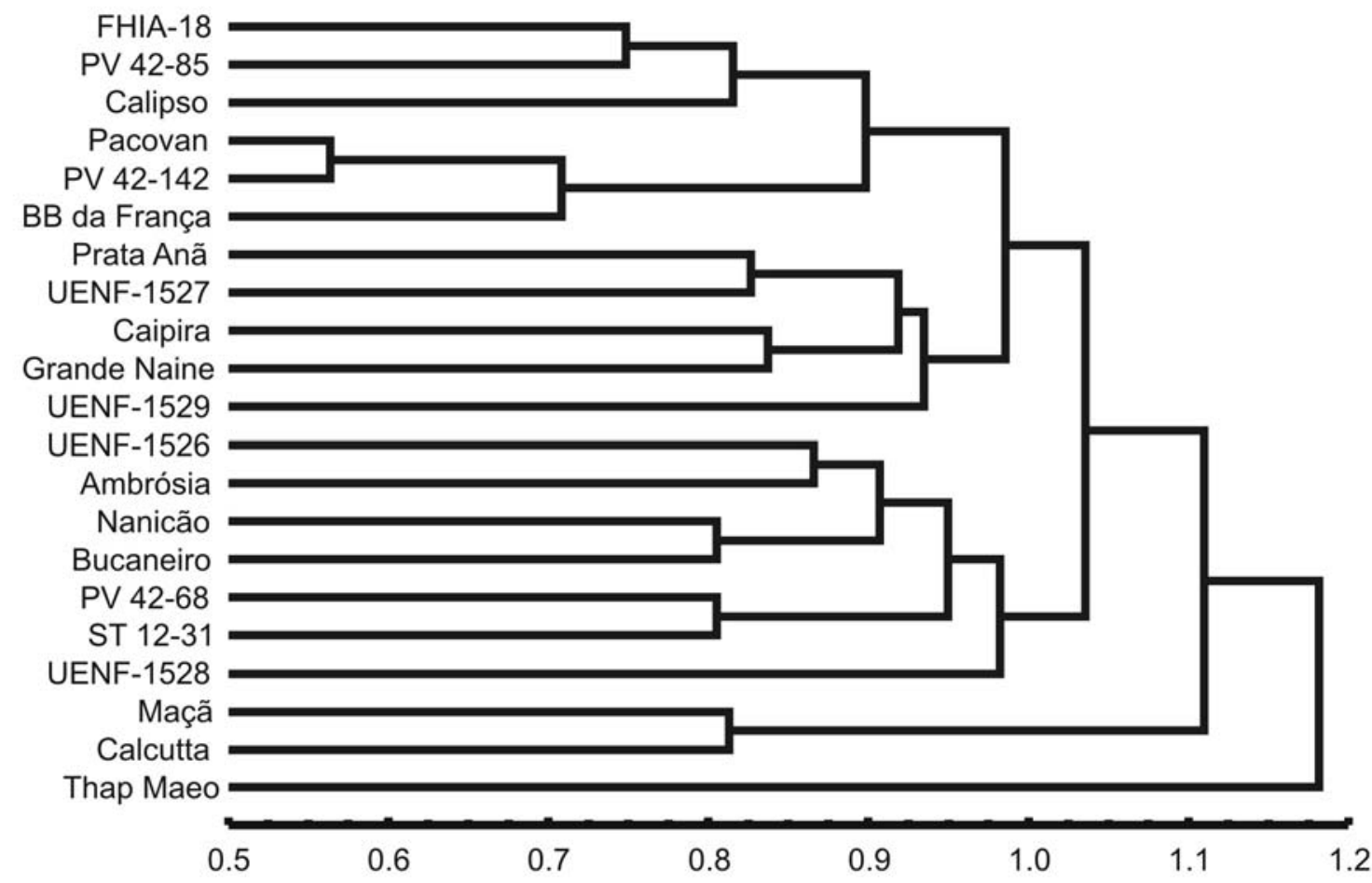

FIGURA 2 - Dendograma da dissimilaridade genética de 21 genótipos de bananeira, com base em marcadores RAPD, obtido pelo método UPGMA, utilizando a distância do complemento aritmético do índice de Jaccard. 
TABELA 1 - Lista dos iniciadores polimórficos e das marcas monomórficas, polimórficas e totais geradas por cada um deles. Caracterização quanto ao tamanho dos fragmentos das marcas polimórficas (pb).

\begin{tabular}{|c|c|c|c|c|}
\hline Primer & Marca monomórfica & $\begin{array}{c}\text { Marca } \\
\text { polimórfica }\end{array}$ & Marcas totais & $\begin{array}{l}\text { Tamanho marca } \\
\text { polimórfica (pb) }\end{array}$ \\
\hline OPA 05 & 0 & 3 & 3 & $2450 / \mathrm{a}-2500 / \mathrm{b}-1250$ \\
\hline OPA 10 & 0 & 1 & 1 & 1250 \\
\hline OPA 17 & 1 & 1 & 2 & 1350 \\
\hline OPA 18 & 0 & 3 & 3 & $1000 / \mathrm{a}-2850 / \mathrm{b}-2800$ \\
\hline OPA 19 & 0 & 4 & 4 & $2200 / \mathrm{a}-2450 / \mathrm{b}-1100$ \\
\hline OPA 20 & 0 & 3 & 3 & $2100 / \mathrm{a}-1200 / \mathrm{b}-1000$ \\
\hline OPB 05 & 0 & 3 & 3 & $1500 / \mathrm{a}-1500 / \mathrm{b}-1200$ \\
\hline OPB 06 & 1 & 1 & 2 & 1200 \\
\hline OPB 07 & 0 & 3 & 4 & $1200 / \mathrm{a}-1050 / \mathrm{b}-1300$ \\
\hline OPB 08 & 0 & 4 & 4 & $2500 / \mathrm{a}-2000 / \mathrm{b}-1100 / \mathrm{c}-2100$ \\
\hline OPB 09 & 0 & 2 & 2 & 2000/a-900 \\
\hline OPB 11 & 1 & 2 & 3 & $1000 / a-900$ \\
\hline OPB 12 & 2 & 4 & 6 & $1550 / \mathrm{a}-1050 / \mathrm{b}-1000$ \\
\hline OPB 13 & 1 & 2 & 3 & $1000 / a-1350$ \\
\hline OPB 14 & 1 & 1 & 2 & 2550 \\
\hline OPB17 & 1 & 1 & 2 & 1000 \\
\hline OPB 19 & 0 & 2 & 2 & $2500 / \mathrm{a}-2000$ \\
\hline OPC 01 & 0 & 1 & 1 & 2000 \\
\hline OPC 02 & 0 & 2 & 2 & $1050 / \mathrm{a}-900$ \\
\hline OPC 04 & 0 & 3 & 3 & $2200 / \mathrm{a}-1250 / \mathrm{b}-900$ \\
\hline OPC 11 & 1 & 2 & 3 & $1200 / \mathrm{a}-1050$ \\
\hline OPC 12 & 2 & 3 & 5 & $1250 / \mathrm{a}-1050 / \mathrm{b}-900$ \\
\hline OPD 02 & 1 & 2 & 3 & $1450 / \mathrm{a}-1200$ \\
\hline OPD 03 & 0 & 3 & 3 & $1200 / a-1000 / b-900$ \\
\hline OPD 04 & 4 & 3 & 7 & $2100 / \mathrm{a}-2100 / \mathrm{b}-2100$ \\
\hline OPD 05 & 1 & 3 & 4 & $2500 / \mathrm{a}-2000 / \mathrm{b}-1100$ \\
\hline OPAA 03 & 0 & 3 & 3 & $2000 / \mathrm{a}-2500 / \mathrm{b}-2200$ \\
\hline OPAA 11 & 0 & 3 & 3 & $2200 / \mathrm{a}-2100 / \mathrm{b}-2000$ \\
\hline OPAA 16 & 2 & 1 & 3 & 1000 \\
\hline OPAA 17 & 0 & 3 & 3 & $1200 / \mathrm{a}-3500 / \mathrm{b}-1000$ \\
\hline OPAB 18 & 0 & 3 & 3 & $1100 / \mathrm{a}-1000 / \mathrm{b}-900$ \\
\hline TOTAL & 19 & 75 & 94 & \\
\hline
\end{tabular}

bp: pares de base

$\mathrm{a}, \mathrm{b}, \mathrm{c}, \mathrm{d}-$ utilizado para diferenciar marcas geradas pelo mesmo iniciador, fabricante Operon.

\section{CONCLUSÕES}

1-Os resultados mostraram que os marcadores moleculares RAPD foram eficazes em revelar a existência de diversidade genética entre os 21 genótipos de bananeira.

2-Com base nestes resultados, podem-se estabelecer critérios para cruzamento entre os referidos genótipos com boas perspectivas de explorar a diversidade encontrada em tal grupo de genótipos, sendo também possível rever a correta identificação dos vários acessos introduzidos na coleção de germoplasma.

\section{REFERÊNCIAS}

CROUCH, J. H.; VUYLSTEKE, D.; ORTIZ, R. Perspectives on the application of biotechnology to assist the genetic enhancement of plantain and banana (Musa spp.). Electronic Journal of Biotechnology, Vaparaíso, v.1, n.1, p.11-22, 1998.
CRUZ, C.D. Programa Genes: versão Windows: aplicativo computacional em genética e estatística. Viçosa: UFV, 2001. 648p. DAMASCO, O. P.; GRAHAM, G. C.; HENRY, R. J.; ADKINS, S. W.; SMITH, M. K.; GODWIN, I. D. Random amplified polymorphic DNA (RAPD) detection of dwarf off-types in micropropagated Cavendish (Musa spp. AAA) bananas. Plant Cell Reports, Berlin, v.16, p.118-123, 1996.

DE JESUS, N. O.; CÂMARA, T. R.; FERREIRA, C.F.; SILVA, S.O.; PESTANA, K.N.; SOARES, T.L. Diferenciação molecular de cultivares elites de bananeira, Pesquisa Agropecuária Brasileira, Brasília, v.41, n.12, p.1739-1748, 2006.

DOYLE, J.J.; DOYLE, J. L. Isolation of plant DNA from fresh tissue. Focus, Nairobi, v.12, p.13-15, 1990.

FERREIRA, C.F.; SILVA, S.O.; SOBRINHO, N.P.D.; DAMASCENA, S.C.S.; ASSIS, F.S., ALVES, A.O., PAZ, O.P. Molecular characteization of banana (AA) diploids with contrasting levels of black and yellow sigatoka resistance. American Journal of Applied Sciences, New York, v.1, n.4, p.276-278, 2004. 
FERREIRA, M.E.; GRATTAPAGLIA, D. Introdução ao uso de marcadores moleculares em análise genética. 2. ed. Brasília: EMBRAPA-CENARGEN, 1998.p. 220.

HOWELL, E. C.; NEWBURY, H. J.; SWENNEN, R. L.; WITHERS, L. A.; FORD-LLOYD, B. V. The use of RAPD for identifying and classifying Musa germplasm. Genome, Ottawa, v.37, n.2, p.32832, 1994.

LANZA, M.A.; GUIMARÃES, C.T.; SCHUSTER, I. Aplicação de marcadores moleculares no melhoramento genético. Informe Agropecuário, Belo Horizonte, n.21, p.97-108, 2000.

OAKLEY, H.J.; GIBSON, L.F.; GEORGE, A.M.; Co-migration of RAPD-PCD amplicons from Aeromonas hydrophila. FEMS Microbiology Letters, New York, n.164, p.35-38, 1998.

PILLAY, M.; NWAKANMA, D. C.; TENKOUANO, A. Identification of RAPD markers linked to A and B genome sequences in Musa L. Genome, Ottawa, v.43, p.763-767, 2000.

SHARON; D., HILLEL; J., VAINSTEIN; A., LAVI. U. Application of DNA fingerprints for identification and genetic-analysis of Carica papaya and other Carica species. Euphytica, Dordrecht, n.62, v.2, p.119-126, 1992.

SINGH, K.P; \& ROY, D. Identification of novel breast tumorspecific mutation (s) in the q11.2 region of cromosome 17 by RAPD/AP-PCR fingerprinting. Gene, Amsterdan, n.269, p.33-43, 2001.
SILVA, S. O.; SHEPHERD, K.; ALVES, E. J.; DANTAS, J. L. L. Cultivares de banana. In: ALVES, E.J. A cultura da banana: aspectos técnicos, socioeconômicos e agroindustriais. Brasília: EMBRAPA-SPI, 1999, p.85-105.

SILVA, S. O.; SANTOS-SEREJO, J. A. Melhoramento da bananeira para resistência: resultados obtidos pelo melhoramento comercial. In: SIMPÓSIO BRASILEIRO SOBRE A BANANICULTURA, 5., WORKSHOP DO GENOMA MUSA, 1., Paracatu, 2003. p.147155.

URASAKI, N.; TOKUMOTO, M.; TORORA, K.; BAN, Y.; KAYANO, T.; TANAKA, H.; OKU, H.; CHINEN, I.; TERAUCHI, R. A male and hermaphrodite specific RAPD markers for papaya (Carica papaya L.). Theoretical and Applied Genetics, Berlin,v.104, n.2-3, p.281-285, 2002.

VITÓRIA, A.P.; SOUZA FILHO, G.A.; BRESSAN-SMITH, R.; PINTO, F.O.; PAIVA, L.B.; GUIMARÃES, P.S.; OLIVEIRA, M.P.A.; PEREIRA, M.G.; DAHER, R.F. DNA fingerprint of Carica papaya L. genotypes by RAPD markers. Journal of News Seeds, v.6, n.1, p.1-10, 2004.

WELSH, J.; MCCLELLAND, M. Fingerprinting genomes using PCR with arbitrary primers. Nucleic Acids Research, Oxford, v.18, p.7213-7218, 1990.

WILLIAMS, J.G.K.; KUBELIK, A.R.; RAFALSKI, J.A.; TINGEY, S.V. DNA polymorfism amplified by arbitrary primers are useful as genetic markers. Nucleic Acids Research, Oxford, v.18, p.6531$6535,1990$. 